\title{
The Impact of the Great East Japan Earthquake on Japan's Economic Growth
}

\author{
Nariyasu Yamasawa ${ }^{1}$ \\ ${ }^{1}$ Facurty of Management, Atomi University, Tokyo, Japan \\ Correspondence: Nariyasu Yamasawa, Faculty of Management, Atomi University, Tokyo, Japan. Tel: \\ 81-48-478-4110. E-mail: yamasawa@atomi.ac.jp
}

Received: May 8, 2015

Accepted: May 22, 2015

Online Published: July 25, 2015

doi:10.5539/ijef.v7n8p20

URL: http://dx.doi.org/10.5539/ijef.v7n8p20

\begin{abstract}
This study captures the impact of the Great East Japan Earthquake on real monthly gross regional product and is the first attempt to measure the indirect loss caused by this natural disaster. We estimate counterfactual monthly gross regional product (assuming that no disaster occurred) for three disaster-stricken prefectures: Iwate, Miyagi, and Fukushima. The differences between the actual data and the counterfactual data indicate indirect loss or gain. The results indicate a reduction in output followed by a gradual rise in reconstruction demand. As of December 2013, the three prefectures experienced total indirect gains of approximately 3 trillion yen ( 30 billion US dollars). The monthly gross regional product and methodology proposed in this study can help researchers and policymakers to estimate indirect loss or gain about 2 months after a natural disaster occurs.
\end{abstract}

Keywords: great east Japan earthquake, gross regional product, disaster recovery, natural disaster, reconstruction

\section{Introduction}

While the study of the long-term effects of natural disasters is considered very important from theoretical and academic viewpoints, policymakers and researchers need to grasp the prevailing economic conditions as soon as possible after the event in order to plan reconstruction and recovery. Thus, this study measures the impact of one of Japan's most devastating natural disasters, the Great East Japan Earthquake, on short-term economic growth. We develop what we refer to as "real monthly gross regional product (GRP)," which can be estimated at the same time as national gross domestic product (GDP). Officially, annual GRP data are released after a 2-year lag. However, our proposed method of estimating the monthly GRP enables policymakers to monitor economic conditions in real time. By measuring indirect loss, we can assess the damage caused by the earthquake and the degree of reconstruction likely to be required.

The Great East Japan Earthquake, which occurred on March 11, 2011 in Miyagi with a magnitude of 9.0 and an intensity of 7, is the world's third strongest earthquake since 1900, following earthquakes in Chile in 1960 (magnitude 9.5) and Alaska in 1964 (magnitude 9.2). The Great East Japan Earthquake is Japan's biggest earthquake in 1,968 years (Table 1). The earthquake claimed 16,000 lives and 3,000 people remain missing. Furthermore, 130,000 residences were completely destroyed and 240,000 were partially destroyed. On July 24 , 2011, the Cabinet Office estimated the direct loss accruing from the earthquake to be 16.9 trillion yen (169 billion US dollars) (Japan Cabinet Office, 2015). According to The Economist, it is the world's costliest earthquake since 1965 (The Economist Online, 2011).

Of Japan's 47 prefectures, those that experienced damage due to the earthquake are shown in Figure 1, and the worst appear in red, namely, Iwate, Miyagi, and Fukushima. In addition, Fukushima is the location of the Fukushima Daiichi nuclear power plant accident.

The rest of this paper proceeds as follows. In Section 2, I review the related literature. Section 3 explains the data. Section 4 presents the methodology used in this study. Section 5 presents the prefectural data needed for the counterfactual estimation. Sections 6 and 7 discuss the regression results and empirical results. Section 8 concludes. 
Table 1. Major earthquakes in Japan since 1872

\begin{tabular}{lclc}
\hline Date & Magnitude & Earthquake & Maximum Intensity \\
\hline March 14, 1872 & 7.1 & Hamada & Not Available \\
October 28, 1891 & 8.0 & Nobi & 6 \\
October 22, 1894 & 7.0 & Shonai & 5 \\
June 15, 1896 & 8.2 & Meiji-Sanriku & $2 \sim 3$ \\
August 31, 1896 & 7.2 & Rikuu & 5 \\
September 1, 1923 & 7.9 & Great Kanto Earthquake & 6 \\
May 23, 1925 & 6.8 & Kitatajima & 6 \\
March 7, 1927 & 7.3 & Kitatanngo & 6 \\
November 26, 1930 & 7.3 & Kitaizu & 6 \\
March 3, 1933 & 8.1 & Showa-Sanriku & 5 \\
September 10, 1943 & 7.2 & Tottori & 6 \\
December 7, 1944 & 7.9 & Tonankai & 6 \\
January 13, 1945 & 6.8 & Mikawa & 5 \\
December 21, 1946 & 8.0 & Nankai & 5 \\
June 28, 1948 & 7.1 & Fukui & 6 \\
May 26, 1983 & 7.7 & Nihonkai Chubu & 5 \\
July 12, 1993 & 7.8 & Hokkaido Nanseioki & 5 \\
January 17, 1995 & 7.3 & Great Hanshin-Awaji Earthquake & 7 \\
March 11, 2011 & 9.0 & Great East Japan Earthquake & 7 \\
\hline
\end{tabular}

Source. Japan Meteorological Agency (2015).

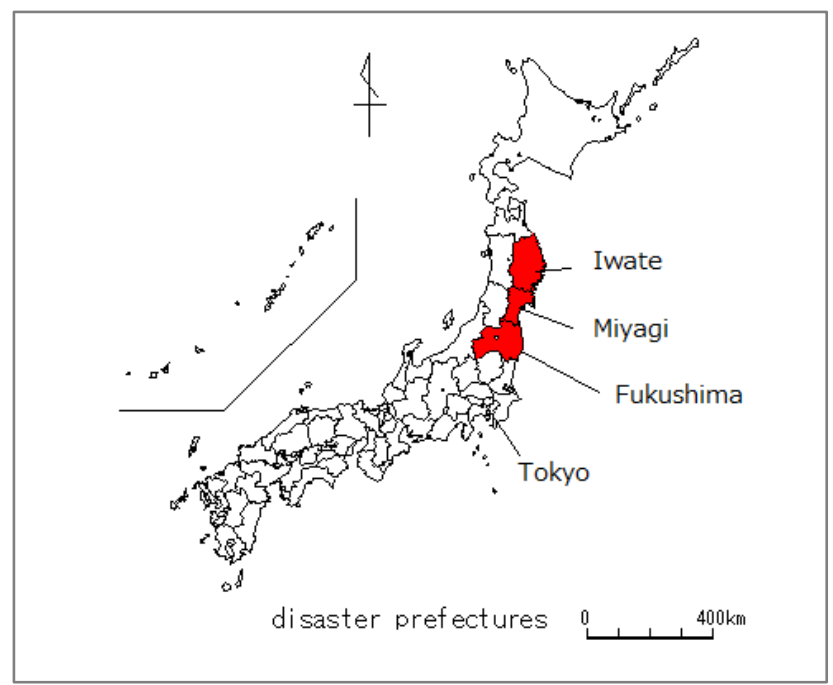

Figure 1. The three prefectures worst affected by the Great East Japan Earthquake (in Red)

\section{Related Literature}

\subsection{Effects of the Disaster}

Previous literature defines the costs that accrue after the occurrence of a natural disaster. For instance, Lazzaroni and Van Bergeijk (2014) conducted a meta-analysis of the economic impact of natural disasters and emphasized the difference between direct and indirect losses accruing from such a disaster. According to Hallegatte and Przyluski (2010), direct loss is the physical loss caused by the disaster, such as the loss of buildings and houses and the damage caused to physical equipment. Direct loss is estimated essentially as repair or replacement costs. On the other hand, indirect loss refers to that not caused by the disaster itself but by its consequences. Thus, indirect loss is the economic loss that accrues in comparison to if the disaster had not occurred.

\subsection{Methodology to Measure the Effects of a Natural Disaster}

There are many ways to measure the effects of a natural disaster, including the (1) engineering approach, (2) 
econometric approach, (3) input-output (IO) table approach, and (4) computable general equilibrium (CGE) approach. Regarding the engineering approach, Brookshire et al. (1997) estimated the direct and indirect losses caused by the Boston Metropolitan Earthquake using the Earthquake Loss Estimation Methodology (HAZUS). The econometric approach was used by Chang (1983) to research the effects of earthquakes on regional governments. Ellson, Milliman, and Blaine Roberts (1984) developed a methodology to estimate the short-term and long-term effects of earthquakes on the regional economy. Lee, Wu, and Wang (2007) studied the contagion effect in financial markets after a natural disaster. Guimaraes, Hefner, and Woodward (1993) estimated the wealth and income effects of Hurricane Hugo. Cavallo, Galiani, Noy, and Pantano (2013) estimated counterfactual data in a natural disaster setting using synthetic control groups. Noy (2009) estimated the macroeconomic consequences of disasters by panel data estimation. With regard to IO tables, Cochrane (1974) used this approach to predict the losses caused by the San Francisco Earthquake. Rose, Benavides, Chang, Szczesniak, and Lim (1997) predicted losses arising from the disaster in Memphis, while Okuyama (2004) analyzed the effects of the Hanshin-Awaji Earthquake using a specially devised IO table. Boisverst (1992) estimated the impacts of earthquakes using an IO table. Cochrane (2004) combined the IO table approach with the HAZUS engineering model. Last, the CGE approach is similar to the IO table method, but it is specifically a behavioral model of a producer and a consumer. Rose and Lim (2002), Rose and Liao (2005), and West and Lenze (1994) followed the CGE model.

\subsection{Long-Term Effects of Natural Disasters}

According to Cavallo and Noy (2009), while the short-run effect of a natural disaster is negative, its long-run effect is inconclusive. Some researchers have emphasized the effect of "creative destruction," a term coined by Schumpeter (Skidmore \& Toya, 2002; Toya \& Skidmore, 2007), while others have focused mainly on the negative impacts arising from disasters. The former found that positive effects, in terms of increasing growth rates, are evident 5 years after the natural disaster has occurred.

\subsection{Studies on the Effects of Japanese Earthquakes}

Horwich (2000) and Okuyama (2004) overviewed the economic effects of the Great Hanshin-Awaji earthquake of 1995 on Kobe. Fujiki and Hsiao (2015) measured the effect of the Great Hanshin-Awaji earthquake using annual GRP data. Asongu (2012) examined the presence of the contagion effect across financial markets after the Great East Japan Earthquake using stock indexes and exchange rates. However, to date, no study has focused on the indirect loss caused by the Great East Japan Earthquake. This study is the first to do so.

\section{Data}

\subsection{Real Monthly GRP}

To measure the short-term impact of the disaster, we need promptly released data. Monthly data are better than quarterly data since we can observe the short-run effects of natural disasters with the former. We estimate monthly GRP using data on expenditure. From the viewpoint of expenditure, GRP comprises private consumption, private equipment investment, public investment, and so on. Since May 2012, the Japanese Cabinet Office has been releasing data on most of the abovementioned GRP components in the form of a monthly index called the Regional Domestic Expenditure Index (RDEI). As the name suggests, the RDEI provides official data for the monthly expenditure index. The methodologies used to estimate the items that comprise the RDEI are described in Table 2. For example, various sales data are used to calculate private consumption. Table 1 presents a summary of the RDEI estimation method.

Table 2. Methodologies used to estimate the various components of the RDEI and the RDEI itself

\begin{tabular}{|c|c|}
\hline Item & Methodology for estimation \\
\hline Private consumption & $\begin{array}{l}\text { Divided by } 44 \text { types of consumption, calculated by multiplying the percentage change by the reference point } \\
\text { ( } 2009 \text { year average) }\end{array}$ \\
\hline $\begin{array}{l}\text { Private residential } \\
\text { investment }\end{array}$ & $\begin{array}{l}\text { Ministry of Land, Infrastructure, Transport and Tourism's "Statistics of Construction Starts of Residential } \\
\text { Properties" }\end{array}$ \\
\hline Private fixed investment & $\begin{array}{l}\text { Estimated usage data on building, construction, machinery, aircraft, motor vehicles, and other transportation } \\
\text { machinery }\end{array}$ \\
\hline Public investment & Ministry of Land, Infrastructure, Transport and Tourism's "Statistics of Construction Order by 47 Prefectures" \\
\hline Real data & Real data compiled using the deflator \\
\hline Change to amount base data & As RDEI is an index $(2005=100)$, we need to change the base amount \\
\hline
\end{tabular}

Source. Tnabae et al. (2012). 
The Cabinet Office does not release data on government consumption and net exports of the RDEI. Thus, we need to estimate these two components. We estimate real monthly GRP by summing up the RDEI, estimated government consumption, and estimated net exports.

We estimate government consumption by panel data estimation. The dependent variables are the government consumption for 47 prefectures, and the explanatory variables are the labor cost of the local government, medical expenditure for people, and care expenditure for aged people. We estimate net exports by panel data estimation. The dependent variables refer to the net exports of 47 prefectures and the explanatory variables are regional demand (the sum of all components of the RDEI) and the industrial production index.

Figure 2 illustrates the cumulative real monthly GRP of 47 prefectures. The black line represents the national GDP. Data on the real monthly GRP can be released at the same time as that on the national GDP, that is, 90 days after the concerned period. The method proposed in this study is very useful as it can provide a very quick estimate of the monthly GRP compared to the official annual GRP. The official annual GRP is released usually by the regional government after a time lag of 2 years after the concerned period.

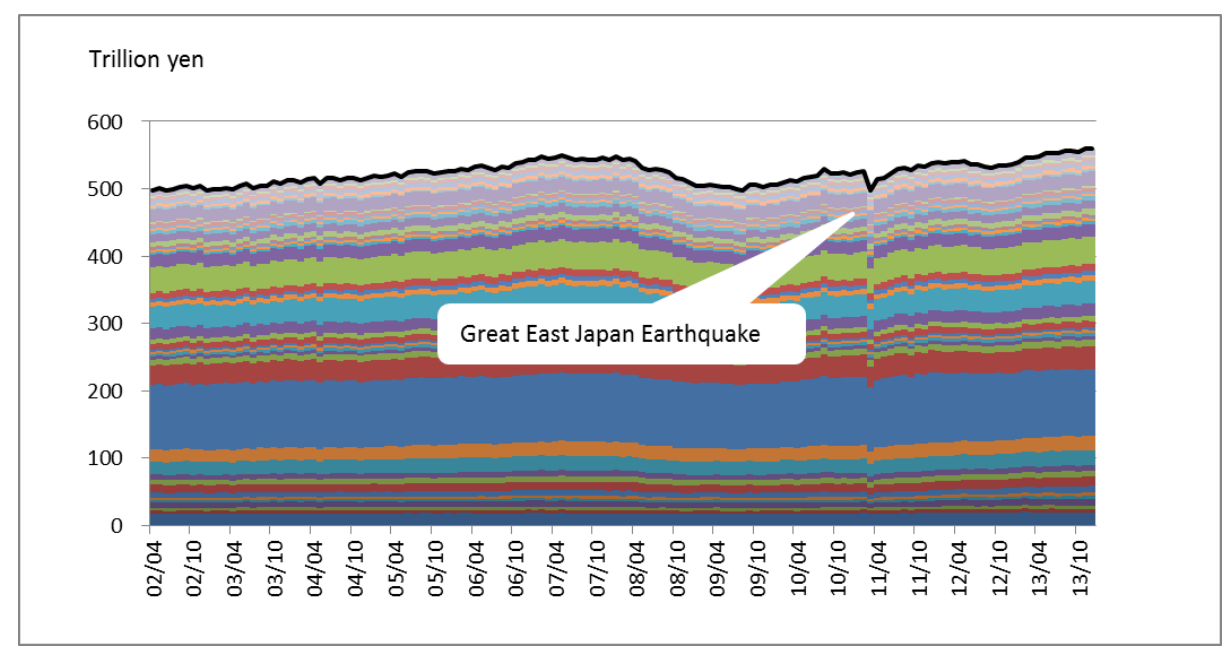

Figure 2. Cumulative real monthly GRP for Japan's 47 prefectures

\section{Methodology}

\subsection{Definitions of Indirect Loss and Indirect Gain}

Our focus is to measure the indirect loss accruing from the Great East Japan Earthquake. As the indirect loss caused by a natural disaster can be calculated using the flow concept (Hallegatte \& Przyluski, 2010), we use the prefectural' GRP. Figure 3 illustrates the cumulative GRP of the worst-affected three prefectures, Iwate, Miyagi, and Fukushima, after the earthquake. The indirect loss is the difference between the actual data (which are available to us) and the baseline. The baseline is the cumulative GRP assuming there was no earthquake, and it is regarded as counterfactual data. We see that the cumulative GRP for the three worst-affected prefectures exceeds the baseline value. However, additional demand after the disaster emerges because of the stimulus provided by reconstruction. This is called the indirect gain. If both the direct loss and the reconstruction demand are very large, the actual GRP will continue to exceed the baseline over a considerable period. Moreover, the cumulative indirect loss and gain would continue to grow until it almost equals the direct loss. 


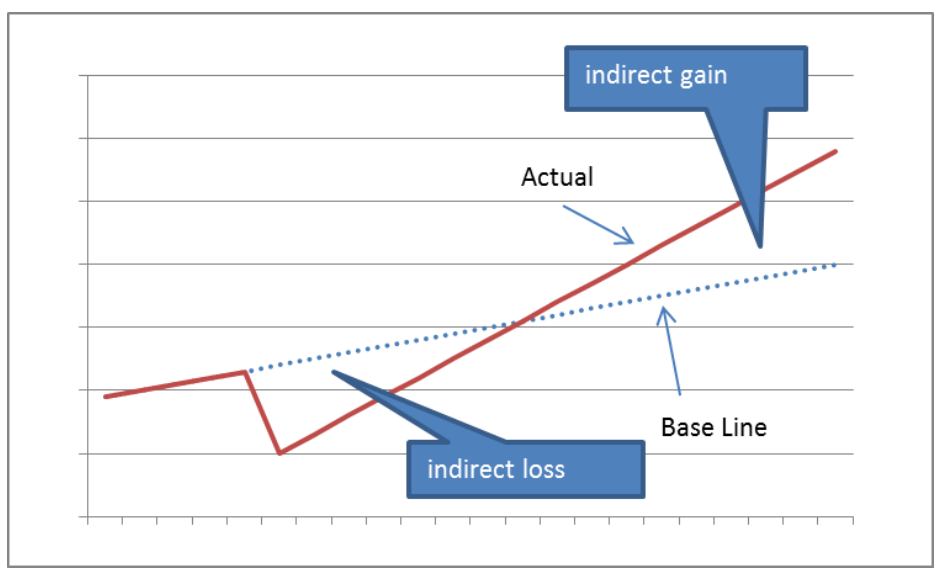

Figure 3. Output after the disaster

Note. The red line denotes actual data, while the dotted blue line is the baseline.

\subsection{Counterfactual Data}

Econometricians have attempted to devise many approaches to construct counterfactuals. Counterfactuals are unobserved data assuming no treatment was received. Abadie, Diamond, and Hainmueller (2010) construct an unobserved model using synthetic control methods for comparative case studies.

$$
Y_{i t}^{N}=\delta_{t}+\theta_{t} Z_{i}+\lambda_{t} \mu_{i+} \varepsilon_{i t}
$$

$Y_{i t}^{N}$ are counterfactuals, $\delta_{t}$ are unknown common factor loadings across units, $z_{i}$ are observed covariates (unaffected by the event), $\theta_{t}$ are unknown parameters, $\lambda_{t}$ are unobserved common factors, $\mu_{t}$ are unknown factor loadings, and $\varepsilon_{t}$ are error terms. In addition, Hsiao, Ching, and Wan (2012, henceforth, HCW) construct an unobserved model

$$
y_{i t}^{0}=b_{i}^{\prime} f_{t}+\alpha_{i}+\epsilon_{i t}
$$

where $f_{t}$ are common factors, $b_{i}^{\prime}$ are constants that may vary across $i, \alpha_{i}$ are fixed individual-specific effects, and $\epsilon_{i t}$ are error terms. Abadie et al. (2010) set two time series, $\theta_{t}$ and $\lambda_{t}$, whereas HCW set one factor, $f_{t}$. According to $\mathrm{HCW}$, to estimate $\theta_{-} t$ and $\lambda_{-} t$ requires some assumptions and the $\mathrm{HCW}$ method can make the parameter estimation easier than synthetic control methods for comparative case studies.

HCW measured the effect of Hong Kong's accession to China in 1997 on the economy of Hong Kong. They estimated the GDP of Hong Kong if there had been no accession to China. Fujiki and Hsiao (2015) applied this methodology to the Great Hanshin-Awaji Earthquake that occurred in 1995 in Japan.

Suppose the observed outcome of a variable $y$ for the $i$-th unit at time $t$ is $y_{i t}$. All $N$ units did not receive the treatment for $t=1, \ldots, T_{1}$, that is, $y_{t}=y_{t}^{0}$. From period $T_{1}+1$ onwards, the first unit received treatment. That is, $y_{1 t}=y_{1 t}^{1}, t=T_{1}+1, \ldots \mathrm{T}$, while the rest of the units did not. Thus, $y_{i t}=y_{i t}^{0}, t=1 \ldots, T ; i=2, \ldots, N$. HCW suggest predicting $\hat{y}_{1 t}^{0}$ as counterfactual data without the treatment, as seen below.

$$
\hat{y}^{0}{ }_{1 t}=E\left(y_{1 t}^{0} \mid \underline{\tilde{y}}_{t}\right)=\mathrm{a}+\underline{\mathrm{b}}^{\prime} \underline{\tilde{y}}_{t}^{\prime}\left(t=T_{1}+1, \ldots, T\right)
$$

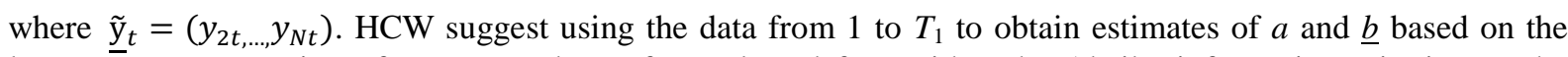
least squares regression of $y_{1 t}$ on a subset of $\underline{y}_{t}$, selected from either the Akaike information criterion or the Bayesian information criterion. Then, we can estimate the treatment effects after period $T_{1}+1$ as

$$
\Delta t=y_{1 t}-\hat{y}_{1 t}^{0}\left(\mathrm{t}=T_{1}+1, \ldots, T\right)
$$

We apply HCW's method to the monthly GRP of Iwate, Miyagi, and Fukushima prefectures before and after the Great East Japan Earthquake. That is, $y_{i t}$ is the real monthly GRP, and the earthquake serves as the "treatment" (see also Subsection 4.3).

\subsection{Calculating Indirect Loss and Gain}

Suppose $y_{1 t}$ is output of one of the three abovementioned prefectures, and $\hat{y}_{1 t}^{0}$ represents the counterfactual data (in case no disaster occurred). Then, indirect loss $I L_{t}$ can be calculated as

$$
I L_{t}=y_{1 t}-\hat{y}_{1 t}^{0}
$$


If $y_{1 t}>\hat{y}_{1 t}^{0}, I L_{t}$ equals indirect gain. This is the treatment effect HCW referred to. After the earthquake, actual data $y_{1 t}$ appear below the baseline. However, if the demand for reconstruction is large, the actual data can be plotted beyond the baseline $\hat{y}_{1 t}^{0}$. Several periods later, indirect loss transforms into indirect gain. In addition, we calculate the total indirect loss $\left(K I L_{t}\right)$ by adding indirect losses from the time the disaster occurred $(t=1)$ to the present $(t=n)$. We divide $I L_{t}$ by 12 , because the estimated real monthly GRP are annualized data.

$$
K I L_{t}=\sum_{t=1}^{t=n}\left(\frac{I L_{t}}{12}\right)
$$

The total indirect loss becomes negative just after the disaster but becomes positive when there is indirect gain. Thus, these data provide a good indication of the increase in the demand for reconstruction.

\section{Prefectural Data Needed for Counterfactual Estimation}

According to $\mathrm{HCW}$, counterfactual data can be estimated using data that receive no treatment. In this study, in order to find the data that receive no treatment, we distinguished between strongly damaged prefectures and less damaged prefecture using the Chow test (Chow, 1960). This is the contribution of this study. We supposed that if the growth rates of some prefectures remained unchanged before and after the earthquake, those prefectures might be considered to have suffered less damage from the earthquake. The estimation equation for each prefecture is:

$$
\log \left(y_{t}\right)=\alpha+\beta T_{t}
$$

where $y_{t}$ is the prefecture's real GRP, $T_{t}$ is the trend variable, and $\alpha$ and $\beta$ are coefficients.

The estimation period is from March 2009, which marks the end of the official business cycle, to December 2013. The breaking point is March 2011. The null hypothesis is " $\beta$ is the same before and after the breaking point." The white, light blue, and dark blue portions in Figure 4 indicate rejection of the null hypothesis at the $1 \%, 5 \%$, and $10 \%$ significance levels, respectively. The prefectures in white were damaged severely by the earthquake, while those colored dark blue were not damaged. The latter are located a considerable distance away from the prefectures in white and/or are far from the hypocenter. We chose 15 prefectures, namely Akita, Aomori, Ehime, Gifu, Hokkaido, Hyogo, Ishikawa, Kagoshima, Kochi, Kumamoto, Oita, Shizuoka, Tokushima, Wakayama, and Yamanashi, as sources of counterfactual data against the 3 severely damaged prefectures of Iwate, Miyagi, and Fukushima.

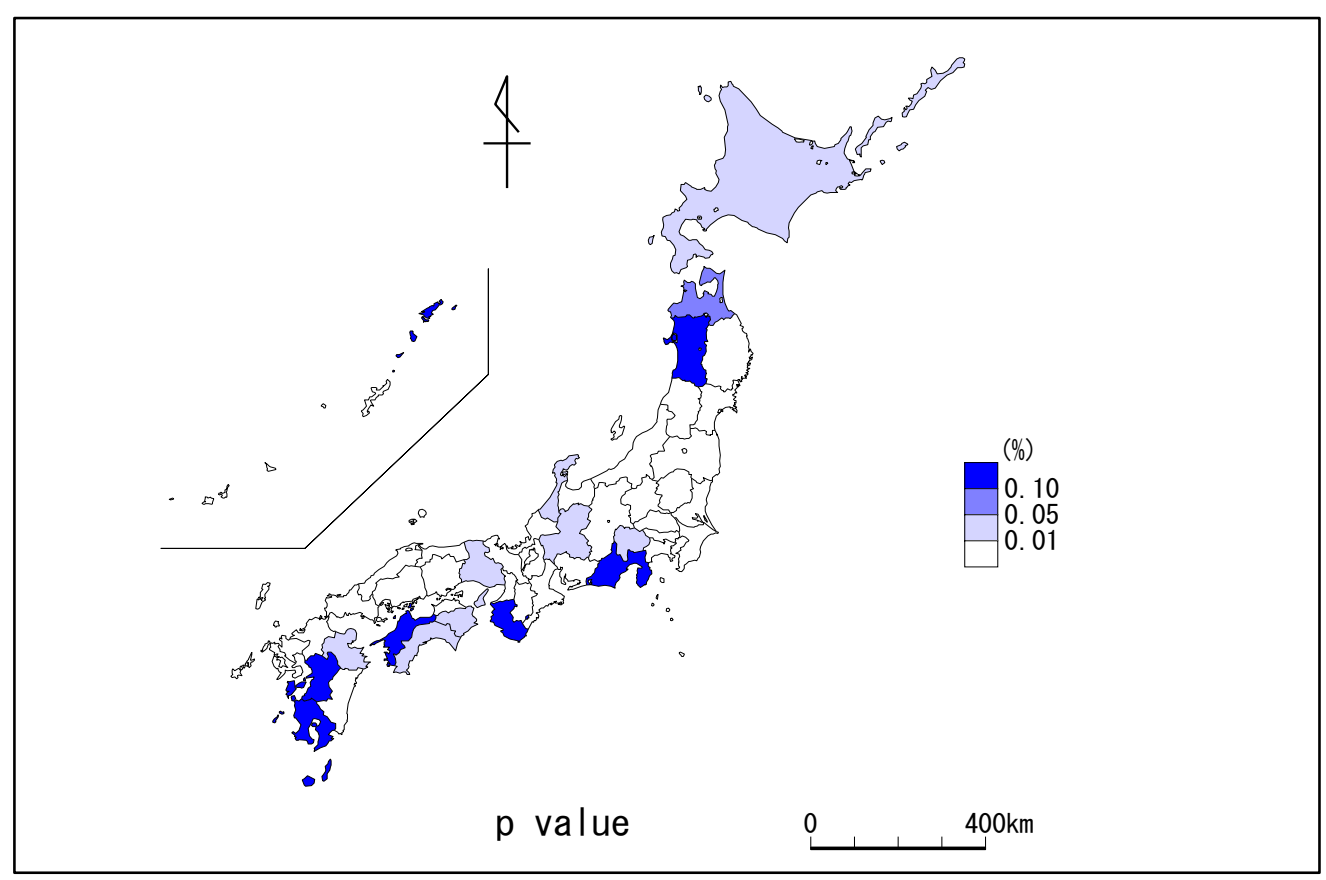

Figure 4. Result of the Chow test

Note. The null hypothesis is "The GRP growth rate shows the same trend before and after the earthquake." The prefectures in white were rejected at the $1 \%$ significance level. Those in light blue and medium blue were rejected at the $5 \%$ and the $10 \%$ significance level respectively. The prefectures colored dark blue were not rejected at the $10 \%$ significance level. 


\section{Regression Results}

Dependent variable $y_{1 t}$ refers to the GRP of the prefectures damaged severely by the earthquake, that is, Iwate, Miyagi, and Fukushima. The explanatory variables $y_{2 t}, y_{3 t}, \ldots$ are the GRPs of the 15 prefectures that suffered comparatively less damage. $a$ is constant; $b_{2}, b_{3}, \ldots$ are coefficients; and $e_{t}$ is the residual term. Note that there is no standard rule to help us fix the number of prefectures while estimating counterfactual data. We choose four prefectures as the initial choice, and we consciously avoid selecting many explanatory variables to avoid multi-collinearity issues.

$$
y_{1 t}=\mathrm{a}+b_{2} y_{2 t}+b_{3} y_{3}+b_{4} y_{4}+b_{5} y_{5}+\mathrm{e}_{t}\left(t=T_{1}+1, \ldots, T ; \text { where } t=1, \ldots, T\right)
$$

For each prefecture, we estimate all combinations of these 4 of the 15 prefectures $(1,365$ cases) and select the combination with the highest $R^{2}$ value. Then, we exclude variables with negative coefficients. The estimation results appear in Table 3.

For Iwate prefecture, among prefectures that suffered less damaged, Ehime and Shizuoka prefectures are selected. Because the dependent variable and explanatory variables are logarithm, the coefficient 0.397 of Ehime and 0.467 of Shizuoka indicate elasticity. In addition, it is interpreted that the growth rate of Iwate GRP is the weighted average of the growth rates of Ehime and Shizuoka prefectures. The weight is 0.397 for Ehime and 0.467 for Shizuoka.

For Miyagi prefecture, the coefficient of Ehime is 0.302 and that of Hyogo is 0.352 . The two prefectures are given about the same weight. The weight for Ishikawa prefecture is small at 0.149. For Fukishima prefecture, the largest weight is for Shizuoka, while the weights for Wakayama and Ishika are 0.273 and Ishikawa 0.340, respectively.

Except Fukushima, the $R^{2}$ values for the other combinations are not very high, but the $t$-values of explanatory variables are satisfactory.

Table 3. Ordinary least squares regressions based on the log GRP of Iwate, Miyagi, and Fukushima prefectures

\begin{tabular}{|c|c|c|c|c|c|c|c|c|}
\hline $\begin{array}{l}\text { Method: Ordinary Le } \\
\text { Sample: } 2002 \mathrm{M} 04-20 \\
\text { Included observations }\end{array}$ & $\begin{array}{l}\text { t Squares } \\
1 \mathrm{M} 02 \\
107\end{array}$ & & & & & & & \\
\hline Dependent Variables & \multicolumn{2}{|c|}{ Iwate } & Dependent Variables & \multicolumn{2}{|c|}{ Miyagi } & Dependent Variables & \multicolumn{2}{|c|}{ Fukushima } \\
\hline Constant & -0.366 & $* * *$ & Constant & 0.407 & $* * *$ & Constant & -0.232 & $* * *$ \\
\hline Ehime & 0.397 & $* * *$ & Ehime & 0.302 & $* * *$ & Shizuoka & 0.496 & $* * *$ \\
\hline \multirow[t]{2}{*}{ Shizuoka } & 0.467 & $* * *$ & Hyogo & 0.352 & $* * *$ & Wakayama & 0.273 & $* * *$ \\
\hline & & & Ishikawa & 0.149 & $* * *$ & Ishikawa & 0.340 & $* * *$ \\
\hline$R^{2}$ & 0.547 & & & 0.546 & & & 0.891 & \\
\hline Adjusted $R^{2}$ & 0.538 & & & 0.532 & & & 0.888 & \\
\hline
\end{tabular}

Note. $* p<0.1$,** $p<0.05$, *** $p<0.01$.

\section{Empirical Results}

\subsection{GRP and Baseline}

Figure 5 shows the actual GRP of Iwate, Miyagi, and Fukushima. The thin red lines indicate the baselines, namely, counterfactual data assuming there was no earthquake. The baseline is estimated by other prefectures' GRP. After the earthquake, these prefectures are not damaged much by the earthquake. The baseline trend seems to be unchanged before and after the earthquake. When there is a negative difference between the actual and counterfactual data, it indicates an indirect loss, and when there is a positive difference, it indicates an indirect gain.

As Figure 5 shows, the GRP of all three prefectures dropped sharply after the earthquake. This is attributable to the destruction of production equipment and a massive break in the industrial supply chain for the whole of Japan.

The GRP of all three prefectures gradually increased after shrinking consistently for several months. Indeed, the GRP of Iwate and Fukushima continued to increase at the time of writing this paper, while that of Miyagi stopped increasing. An analysis of the GRP components reveals that increased public works contributed primarily to these increases in the prefectures' GRP. 

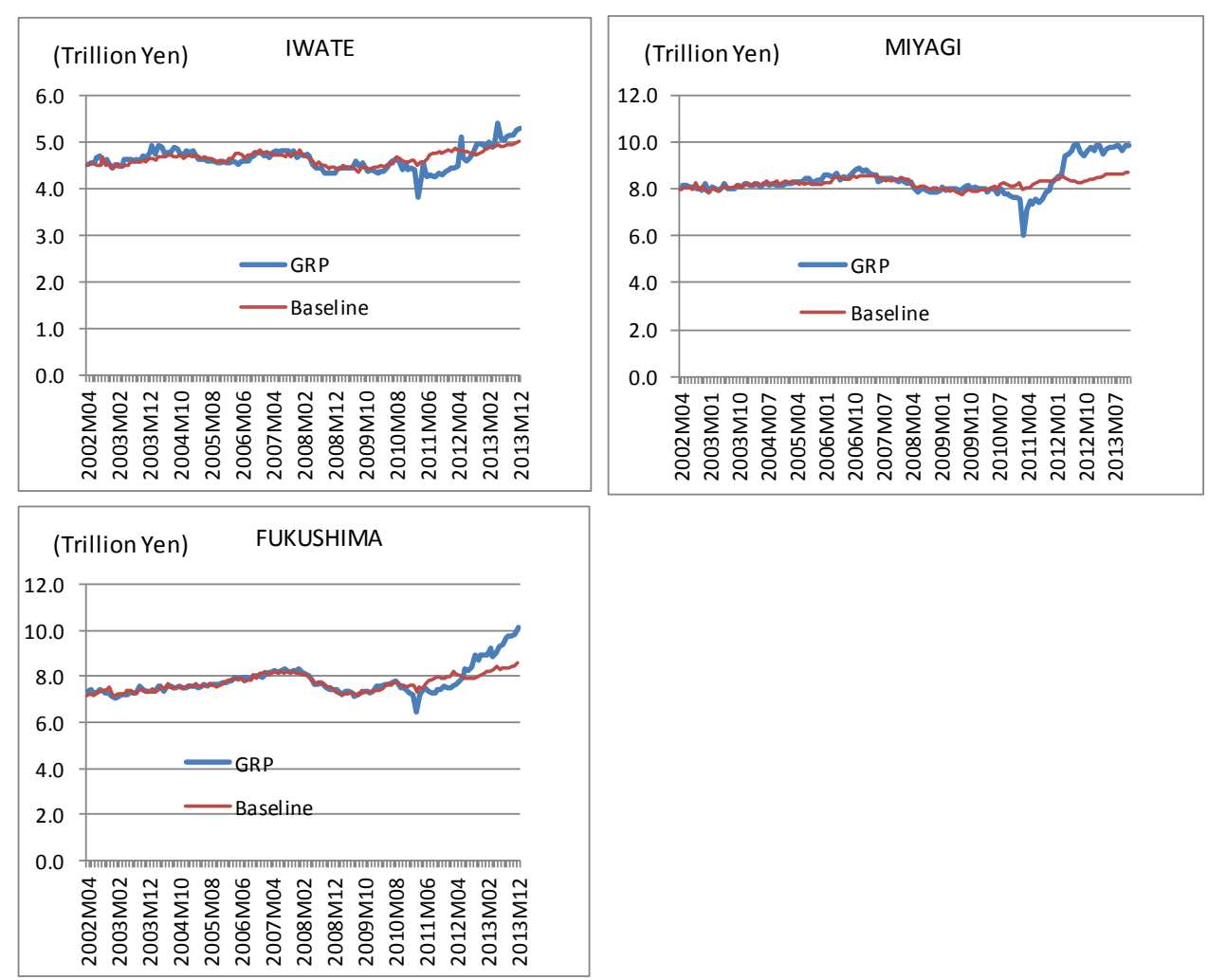

Figure 5. Real monthly GRP and baselines for Iwate, Miyagi, and Fukushima

\subsection{Indirect Loss and Gain for the Three Prefectures}

We estimated indirect loss and gain using the method presented in Subsection 4.3. We summarize the indirect losses of the three prefectures in Figure 6. Counterfactual data just after the earthquake, that is, after March 2011, are plotted below the actual data, thus, indicating indirect losses. After mid-2012, we see the opposite, that is, the actual data overtake the counterfactual data. This means that reconstruction demand increased, and indirect gains emerged. Currently, the values of the actual data continue to exceed the baseline, thus, implying that reconstruction demand still exists. This is likely to be the case for a fairly long time and means that the earthquake increases the growth rate after mid-2012 for more than 1.5 years.

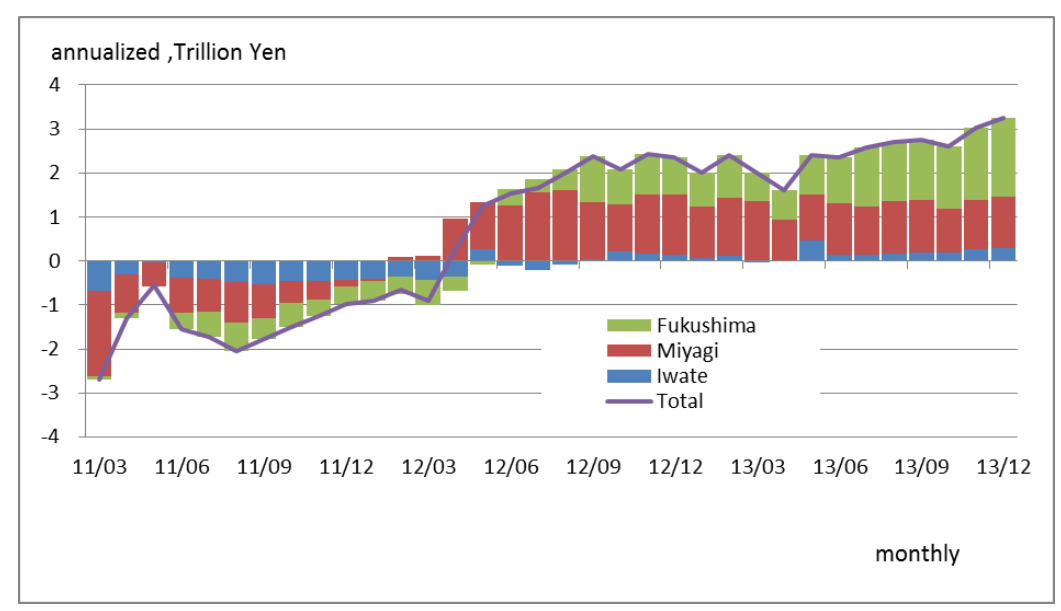

Figure 6. Indirect loss and gain 
Figure 7 illustrates the cumulative indirect loss and gain, which represents reconstruction demand. We plot Figure 7 using the data for the indirect losses from Figure 6. Towards the end of 2013, the total reconstruction demand for the three prefectures amounted to approximately 2.5 trillion yen ( 25 billion US dollars).

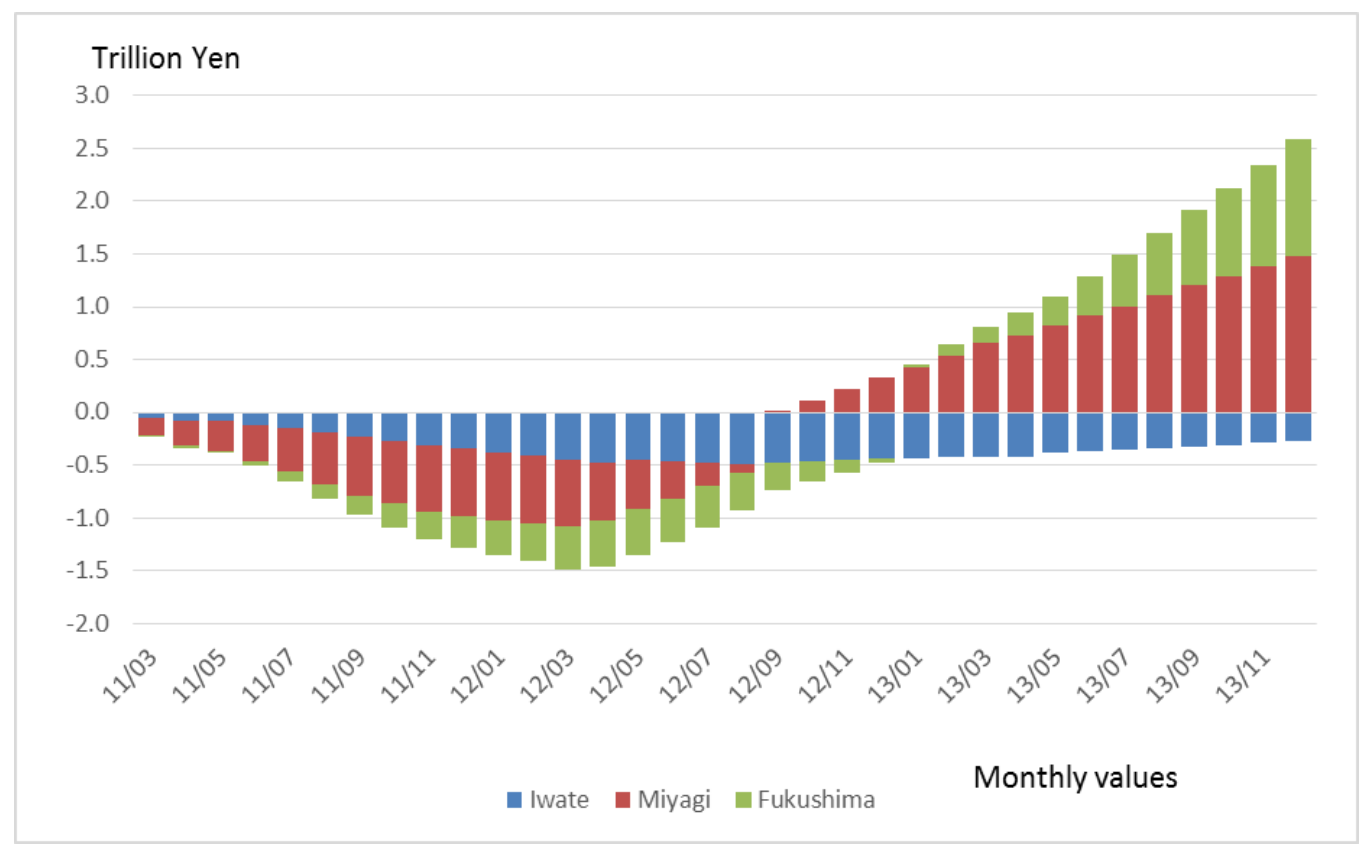

Figure 7. Cumulative indirect loss

\section{Conclusion}

This is the first study to estimate the impact of the Great East Japan Earthquake on the economic growth of the worst-affected prefectures. As the magnitude of the earthquake was 9.0, making it Japan's biggest earthquake since 1868 , it is worthwhile to estimate the indirect loss caused by such a devastating earthquake.

We used the monthly GRP of 47 prefectures and focused on the output of 3 of the worst-affected prefectures, Iwate, Miyagi, and Fukushima. The GRP of the other prefectures was estimated using counterfactual data (i.e., assuming there was no earthquake), following the method devised by HCW. Following the arguments of Fujiki and Hsiao (2015), we applied this method to understand the effect of the earthquake on regional economies.

Then, we distinguished those prefectures that were less damaged by the earthquake using Chow's (1960) test. Four prefectures were chosen, and we estimated counterfactual data for Iwate, Miyagi, and Fukushima by regressing the data of the less-damaged prefectures. The differences between the actual data and the counterfactual data indicate indirect loss or indirect gain. We found that the actual data could be plotted above the counterfactual baseline 2 years after the earthquake. In other words, indirect gain amounting to 3 trillion yen (30 billion US dollars) emerged 2 years after the earthquake occurred.

The methodology proposed in this study could help us to estimate or predict indirect loss or gain about 2 months after a natural disaster. Thus, the findings of this study are useful to policymakers and researchers in the field of reconstruction planning and disaster recovery.

However, this study has some limitations. First, our estimation method of calculating the counterfactual data using HCW's method was for only four less-damaged prefectures, whereas all prefectures were affected by the earthquake to some extent. We could have conducted the estimation differently, for example, by selecting a different number of less-damaged prefectures.

The second limitation concerns the reliability of the GRP data. We used monthly GRP and showed that reconstruction demand is very strong and regional economies have been improving. However, certain indicators suggest that the regional economies are stagnating. For example, the Index of Industrial Production does not show clear recovery. Thus, additional research is needed to confirm the extent of reconstruction demand.

Third, we should refer to the reconstruction period. Guimaraes et al. (1993) noted that for major disasters, 
reconstruction effects might last for more than 2 years. Our study indicates that the actual data do not return to baseline levels, indicating that reconstruction continued even after about 3 years had elapsed after the earthquake. However, our study does not calculate the total indirect loss. Thus, more research is required to understand the long-term effects of the earthquake.

\section{Acknowledgments}

This work was supported by Japan Society for the Promotion of Science KAKENHI Grant Number 25380318.

\section{References}

Abadie, A., Diamond, A., \& Hainmueller, J. (2010). Synthetic control methods for comparative case studies: Estimating the effect of California's tobacco control program. Journal of the American Statistical Association, 105, 493-505. http://dx.doi.org/10.1198/jasa.2009.ap08746

Asongu, S. A. (2012). The 2011 Japanese earthquake, tsunami and nuclear crisis: Evidence of contagion from international financial markets. Journal of Financial Economic Policy, 4(4), 340-353. http://dx.doi.org/10.1108/17576381211279307

Boisverst, R. (1992). Indirect losses from a catastrophic earthquake and local, regional, and national interest. In National Earthquake Hazards Reduction Program, Indirect economic consequences of a catastrophic earthquake (pp. 207-265). Washington, DC: Federal Emergency Management Agency.

Brookshire, D. S., Chang, S. E., Cochrane, H., Olson, R. A., Rose, A., \& Steenson, J. (1997). Direct and indirect economic losses from earthquake damage. Earthquake Spectra, 13(4), 683-701. http://dx.doi.org/10.1193/1.1585975

Cavallo, E., Galiani, S., Noy, I., \& Pantano, J. (2013). Catastrophic natural disasters and economic growth. Review of Economics and Statistics, 95(5), 1549-1561. http://dx.doi.org/10.1162/REST_a_00413

Cavallo, E., \& Noy, I. (2009). The economics of natural disasters: A survey. Research Department Publications 4649, Inter-American Development Bank, Research Department. http://dx.doi.org/10.2139/ssrn.1817217

Chang, S. (1983). Disasters and fiscal policy: Hurricane impact on municipal revenue. Urban Affairs Quarterly, 18(4), 511-523. http://dx.doi.org/10.1177/004208168301800407

Chow, G. C. (1960). Tests of equality between sets of coefficients in two linear regressions. Econometrica, 28(3), 591-605. http://dx.doi.org/10.2307/1910133

Cochrane, H. C. (1974). Predicting the economic impacts of earthquakes. In H. C. Cochrane, J. E. Haas, M. J. Bowden, \& R. W. Kates (Eds.), Social Science Perspectives on the Coming San Francisco Earthquake, Natural Hazards Research Paper No. 25, NHRAIC, Boulder, CO: University of Colorado.

Cochrane, H. (2004). Economic loss: Myth and measurement. Disaster Prevention and Management: An International Journal, 13(4), 290-296. http://dx.doi.org/10.1108/09653560410556500

Ellson, R., Milliman, J. W., \& Blaine, R. R. (1984). Measuring the regional economic effects of earthquakes and earthquake predictions. Journal of Regional Science, 24(4), 559-579. http://dx.doi.org/10.1111/j.1467-9787.1984.tb01048.x

Fujiki, H., \& Hsiao, C. (2015). Disentangling the effects of multiple treatments-Measuring the net economic impact of the 1995 Great Hanshin-Awaji Earthquake. Journal of Econometrics, 186(1), 66-73. http://dx.doi.org/10.1016/j.jeconom.2014.10.010

Guimaraes, P., Hefner, F. L., \& Woodward, D. P. (1993). Wealth and income effects of natural disasters: An econometric analysis of Hurricane Hugo. Review of Regional Studies, 23, 97-114.

Hallegatte, S., \& Przyluski, V. (2010). The economics of natural disasters: Concepts and methods. Policy Research Working Paper No. WPS 5507, Washington DC: World Bank. http://dx.doi.org/10.1596/1813-9450-5507

Horwich, G. (2000). Economic lessons of the Kobe earthquake. Economic Development and Cultural Change, 48(3), 521-543. http://dx.doi.org/10.1086/452609

Hsiao, C., Steve Ching, H., \& Wan, S. K. (2012). A panel data approach for program evaluation: Measuring the benefits of political and economic integration of Hong Kong with Mainland China. Journal of Applied Econometrics, 27(5), 705-740. http://dx.doi.org/10.1002/jae.1230

Japan Cabinet Office. (2015, April 9). Estimation of the amount of damage of the Great East Japan Earthquake. Retrieved from http://www.bousai.go.jp/2011daishinsai/pdf/110624-1kisya.pdf (in Japanese) 
Japan Meteorological Agency. (2015, April 3). Major Earthquakes in Japan since 1872. Retrieved from http://www.data.jma.go.jp/svd/eqev/data/higai/higai-1995.html (in Japanese)

Lazzaroni, S., Van Bergeijk, P. A. G. (2014). Natural disasters' impact, factors of resilience and development: A metaanalysis of the macroeconomic literature. Ecological Economics, 107, 333-346. http://dx.doi.org/10.1016/j.ecolecon.2014.08.015

Lee, H., Wu, H., \& Wang, Y. (2007). Contagion effect in financial markets after the South-East Asia tsunami. Research in International Business and Finance 21, 281-296. http://dx.doi.org/10.1016/j.ribaf.2006.05.001

Noy, I. (2009). The macroeconomic consequences of disasters. Journal of Development Economics, 88(2), 221-231. http://dx.doi.org/10.1016/j.jdeveco.2008.02.005

Okuyama, Y. (2004). Modeling spatial economic impacts of an earthquake: Input-output approaches. Disaster Prevention and Management: An International Journal, 13(4), 297-306. http://dx.doi.org/10.1108/09653560410556519

Rose, A., Benavides, J., Chang, S. E., Szczesniak, P., \& Lim, D. (1997). The regional economic impact of an earthquake: Direct and indirect effects of electricity lifeline disruptions. Journal of Regional Science, 37(3), 437-458. http://dx.doi.org/10.1111/0022-4146.00063

Rose, A., \& Liao, S. (2005). Modeling regional economic resilience to disasters: A computable general equilibrium analysis of water service disruptions. Journal of Regional Science, 45(1), 75-112. http://dx.doi.org/10.1111/j.0022-4146.2005.00365.x

Rose, A., \& Lim, D. (2002). Business interruption losses from natural hazards: Conceptual and methodological issues in the case of the Northridge earthquake. Global Environmental Change Part B: Environmental Hazards, 4(1), 1-14. http://dx.doi.org/10.1016/S1464-2867(02)00012-8

Skidmore, M., \& Toya, H. (2002). Do natural disasters promote long-run growth? Economic Inquiry, 40(4), 664-687. http://dx.doi.org/10.1093/ei/40.4.664

The Economist Online. (2011, March 21). Natural disasters: Counting the cost. Retrieved from http://www.economist.com/blogs/dailychart/2011/03/natural_disasters

Toya, H., \& Skidmore, M. (2007). Economic development and the impacts of natural disasters. Economics Letters, 94(1), 20-25. http://dx.doi.org/10.1016/j.econlet.2006.06.020

Tnabae, Y., Maikimoto, H., Imamura, S., Narita, H., \& Matsushima, K. (2012). Chiikibetsu Sishutsu Sogo Shisu (RDEI) No Shisan Ni Tsuite. Discussion Paper Series DP/12-3, Japan Cabinet Office (in Japanese).

West, C. T., \& Lenze, D. G. (1994). Modeling the regional impact of natural disaster and recovery: A general framework and an application to Hurricane Andrew. International Regional Science Review, 17(2), 121-150. http://dx.doi.org/10.1177/016001769401700201

\section{Copyrights}

Copyright for this article is retained by the author(s), with first publication rights granted to the journal.

This is an open-access article distributed under the terms and conditions of the Creative Commons Attribution license (http://creativecommons.org/licenses/by/3.0/). 